\title{
Did Primary Health Care Doctors Lose the Battle with the Specialist and Consultants?
}

\author{
Manal Ali Ghandour* \\ Department of Health Informatics \& Analytics, Dubai HealthCare City Authority-Regulatory, Dubai
}

Submission: April 24, 2017; Published: May 30, 2017

*Corresponding author: Manal Ali Ghandour, Department of Health Informatics \& Analytics, Dubai HealthCare City Authority-Regulatory, Dubai, Tel: +9714-3838300; Email: Manal.ghandour@dhcr.gov.ae

\section{Opinion}

Many organizations claim to be "Primary Healthcare (PHC) focused" and working on preventive measures and strategies. However, when you look to the number of initiatives or projects planned for preventive medicine (PM) and (PHC) in comparison to secondary and Tertiary care initiatives \& projects, you will notice that Secondary and Tertiary care are getting up to $70 \%$ of the budget or more; thus in some places, one hospital will be a located a budget equal to 100 facilities working in preventive medicine and primary health care. Therefore, unless we see a strategic shift in the budget allocation and that (PM) and (PHC) sectors are allocated $60 \%$ or more of the budget, then I cannot believe that the Healthcare System is "Primary Healthcare \&Preventive Medicine focused" [1].

On the grounds, Primary Healthcare Doctors (PHDs) had lost the battle with specialists and consultants due to different set ups and regulations that results in giving more support and gratitude to the specialist and the consultant while the PHDs get only struggles and I will explain why. There are four perspectives that support the specialists and consultants and make them well equipped with knowledge and environmental factors while making GPs and alike doctors struggle.

The first perspective is, the scope of practice: GP is required to know everything. While the specialist or Consultants (Spec \& Cons) are more in depth prepared to deal with a system or two or one organ. So if Spec \& Cons Can reaches mastery after having 10,000 hours practice in one subject, GPs reach nowhere for the same number of hours, e.g. they will not become specialist or consultant in certain field [2].

Also, from the Environmental perspective: Spec. \& Cons. are given more equipment, can do sophisticated procedures and allowed to request all types of investigations. Also they are provided with specialized intelligent EMR and reasonable appointment time and referrals. In short, Spec. \& Cons. are prepared to succeed, while GPs are provided with basic equipment, basic health record system that is broad and has no sense of intelligence. Also they are booked with many patients for very short time of consultation ranging between 7 to 20 minutes. When GP refers a patient, the patient is treated with least priority and thus booked the last on the Specialist or Consultant's list. Thus GPs are prone for failure and poor outcomes.

Moreover, to be Licensed to Practicee.g in Dubai Healthcare City; GPs should have two years' experience, and one year internship, while Specialist should have 2-5 years' experience and 3years of residency or more. So on minimal level GP with 3 years of proper practice will be competing with Specialist who has 5 years of experience.

Looking into continuing education perspective, the GP needs to keep abreast with very huge knowledge, as one new disease will be discovered in every year (at least) and many drugs are added on yearly bases that he should know. For example, 22 new drugs were approved in 2016 by USA FDA alone and there are many countries who are introducing new medications every year. Lastly GPs are rarely involved in any researches or get any sort of feedback on their services. On the other hand, Specialists rarely encounter discovering a new disease or get 1-2 new drugs released per year. They get different feedbacks from incident reports, pharmacists, researches and audits. So they are helped for internal and external continuous improvements [3].

Hence, as a Patient, if you had the choice where will you go for treatment? Definitely patients prefer to go to consultants and specialists due to all reasons mentioned before. The consultants and specialists are equipped with many success factors, specially speed of appointment, investigations, diagnosis and treatment.

So what solutions we can adapt to improve GP practice? There are many solutions that can be used individually or consequently or all together:

I. Provide EMR systems that classify cases rather than taking them as general cases (chest case, heart case, asthma sheet, pediatric sheet etc. 
II. Impede dictionaries and guidelines in HIS systems, use intelligent differential diagnosis, free lab and radiology access, and add quality checks and auditing to the work processes.

III. Consultant and Specialist are required to have 80CME hours to keep on top of their profession and get renewal of license. GPs should be offered at least, 160CME from their practice hours to keep up to date with medical and technology advances [4].

IV. Segregate GPs into specialties, meaning each doctor gets more cases on certain problems as if he is going to specialize; so we need to have Asthma GP, Heart Problems GP and Diabetes GP. In addition to the general cases they see, they will be able to focus and follow up on certain cases with higher degree of effectiveness and will work closely with one type of specialty and make referral easy and get proper feedback [5].
V. Involve them into more research and case studies building

\section{References}

1. (2009) The Power of Prevention, Chronic Disease...The public health challenge of the 21st century. Center for Disease Control and Prevention.

2. Scope of general practice, What is a GP's scope of Practice? GP options.

3. Novel Drugs Approval for 2016 (2016) FDA, US Food and Drug Administration.

4. License requirements for Physicians and Dentists Guidance for Applicants (2016) DHCR.

5. Oreste Capelli, Silvia Riccomi, Marina Scarpa, Nicola Magrini, Elisabetta Rovatti, et al. (2012) Clinical Audit in Primary Care: From Evidence to Practice. Intech open, Croatia.

\section{Your next submission with Juniper Publishers} will reach you the below assets
- Quality Editorial service

- Swift Peer Review

- Reprints availability

- E-prints Service

- Manuscript Podcast for convenient understanding

- Global attainment for your research

- Manuscript accessibility in different formats

( Pdf, E-pub, Full Text, Audio)

- Unceasing customer service

Track the below URL for one-step submission https://juniperpublishers.com/online-submission.php 